\title{
ICOM \\ A comprehensive and multidisciplinary approach to science communication
}

Reviewed Book

Reviewed by

Abstract

Keywords

DOI
LessmöllmanN, A., DAscal, M. AND Gloning, T. EdS. (2019).

SCIENCE COMMUNICATION.

Berin, Germany and Boston, MA, U.S.A.: De Gruyter Mouton

\section{Erik Stengler}

A comprehensive treatise on science communication from the perspectives of scholars of multiple disciplines, this book contributes a unique compendium of virtually all fields of study that have something to say about the theory and practice of public engagement with science. It is an enriching companion for research, teaching and practice of science communication in all its forms.

History of public communication of science; Science and media; Science communication: theory and models

https://doi.org/10.22323/2.19030702

Submitted: 12th June 2020

Accepted: 15th June 2020

Published: 29th June 2020
There are many very good books on Science Communication that stem from research and practice in the field, so one may ask oneself what does a new volume like this add to the landscape?

In response to this question I venture to say that this is a very necessary volume, that it is not just an addition to the landscape, but rather an essential frame for the field that provides context in terms of theories of knowledge; in terms of the role of science in society and therefore on who does research on science communication and why; in terms of the history of science and of science communication; and not least also from a practical point of view, not just from science communication practitioners and researchers, but also from the perspective of communication science as applied to science communication.

About the latter I cannot resist noting that it is indeed a breath of fresh air to finally see those two terms (communication science and science communication) used in their proper meanings side by side! 
The first chapter provides a perfect example of the context-setting importance of this book, where very clear and specific recommendations for science communication practice are distilled from the philosophy of science. I can tell from my own experience teaching science communication that students are craving discussions on these types of questions. Issues from ontology (what is reality, what is truth, what exists and what doesn't...) and epistemology (how we know the world, the limitations of scientific knowledge, certainty, our ability to know the truth as true...) often come up in class discussions about the relationship between science and society. From a teaching point of view, therefore, this book has the potential to become an important reference work. As the chapter argues: "Without philosophy of science [...] we would face a choice between blind faith and blind mistrust in science".

After philosophy, it's the turn of psychology to shed light on how citizens engage with science and the ever important question of trust in science and scientists (chapter 2); of media and communication studies to explore some very practical yet theory-laden ways in which science communication relates to the media, i.e. has been "medialized" (chapter 3), to provide a broad picture of the empirical research on science communication (chapter 4) and to discuss the impact of digitalization on science communication (chapter 5); of sociology of science to explain the approach of science and technology studies (STS) to research on science communication (chapter 6); of linguistics and semiotics to look into scientific language and science communication (chapter 7) and to analyze terminology in science communication (chapter 8); and of instruction-inspired research to make very specific recommendations on academic writing skills (chapter 9). As can be seen these first 9 chapters, which together constitute section I (of five) of the book, constitute a wellstructured journey from the most abstract ideas to very specific and practical skills.

Section II follows exploring the production, formulation, organization, transmission, publication and discussion of scientific knowledge by scientists for scientists and their use of epistemic genres (chapter 10); of visual representations (chapter 11); and of symbolic notation (chapters 16 and 17). The rest of the section analyzes common practices that are part and parcel of researchers' lives, such as: lectures and presentations (chapter 12); spoken language in general (chapter 13); peer-reviewing (chapter 14); debates on controversies (chapter 15); and grant proposal writing (chapter 18). Even though this section is designated to focus on "internal" science (scholarly) communication, which comprises communication between scientists of the same or different disciplines, it is highly relevant to science communication practice. Not only because chapter 13 explicitly addresses spoken language in communication with the public as well as among peers, but also because science communicators need to understand what scientists think and say to each other as well as their mindsets when it comes to, for example, peer-reviewing or controversies.

Section III is more directly and explicitly focused on the communication of science to the public, in approaches like popularization of science (chapter 19), a deliberately generic term that comprises the vast variety of formats of science communication understood as what we currently call public engagement with science, ranging from popular science books or magazines to citizen science, through online videos, science museums and exhibitions, science festivals, TV shows, and public lectures, to name but a few. While these formats are significantly 
different from each other, the author of this chapter manages to dissect and analyze the phenomenon of popularization of science under a single lens, abstracting out their commonalities (factors) and then unpicking them in order to systematize the elements of the underlying communicative strategies. The following chapters then address more specific areas like science journalism (chapters 20 and 21); public relations (chapter 22); public participation in science, through advising, advocacy and public debates (chapter 23); and presentations in public settings, specifically comparing both presentations, science slams and videos in terms of various aspects, such as interactivity or entertainment value (chapter 24 ).

Even though it is not signposted as such, the combination of sections IV and V feel like a second, separate part in the book, in which time is the thread along which the communication of science is explored. It starts chronologically in the past, with a history of internal science communication (chapter 25), of academic teaching (chapter 26) science and of external science communication (chapter 27). The inclusion of teaching as a conceptual transition between internal and external science communication brings an interesting perspective that highlights the recurring issue of the overlap and interplay between science education and science communication, as masterfully discussed in the context of Emily Dawson's work (and book) on Equity, Exclusion and Everyday Learning [Dawson, 2019]. After the historical approach it is the turn of the present and the future, with chapters on the impact of digital technologies on science communication practices (chapter 28) and on the role of libraries (chapter 29) and social media (chapter 30); scholarly communication in social media (chapter 31); and other current developments and trends in both internal and external science communication that will shape the field in the years ahead of us.

Altogether this is the most comprehensive and multidisciplinary single volume on science communication currently available and as such it is definitely worth being on the shelf of anyone interested in understanding and teaching the topic in its widest possible scope. The chapters are ideal for "first encounters" with each of the topics, approaches or methodologies at slightly more than just the introductory level. Each chapter thoroughly references further work, which makes the reference lists a very useful resource in themselves, enabling pursuit of the specific topics to the next level(s). Inevitably the balance of the content may be skewed to reflect the research interests of the authors but overall it can be said that no angle, approach or practice has been left unexplored in one way or another.

References

Dawson, E. (2019). Equity, exclusion and everyday science learning: the experiences of minoritised groups. London, U.K.: Routledge.

Author

Erik Stengler teaches the courses in the Science Museum Studies Track at the Cooperstown Graduate Program, situating science museums, science centers and planetariums in the wider context of science communication. Stengler is committed to the idea that science museums need to incorporate a new generation of museum professionals with a solid grounding in museum studies to ensure that these institutions remain relevant to society in the 21st century. Stengler has extensive experience in science museum education, programming, exhibition design and 
outreach, having led several large publicly funded projects to take museum activities to underserved communities, including remote islands, prisons, senior citizens and hospitals; or unexpected places, like beaches, music festivals, fun fairs and village squares. Stengler developed a practice-based research interest in Science Museums and also in science in popular culture, most specifically in TV and film. In both areas Stengler has published various articles, book chapters and edited conference proceeding volumes, often in close collaboration with students whom he likes to encourage to present at conferences and meetings.

E-mail: Erik.Stengler@oneonta.edu.

How to cite

Stengler, E. (2020). 'A comprehensive and multidisciplinary approach to science communication'. JCOM 19 (03), R02. https:/ / doi.org/10.22323/2.19030702. 